\title{
Pathogen-Specific Effects of Quantitative Trait Loci Affecting Clinical Mastitis and Somatic Cell Count in Danish Holstein Cattle
}

\author{
L. P. Sørensen, ${ }^{* 1}$ B. Guldbrandtsen, $\dagger$ J. R. Thomasen, $\ddagger$ and M. S. Lund $†$ \\ *University of Copenhagen, Faculty of Life Sciences, Department of Large Animal Sciences, DK-1870 Frederiksberg C, Denmark \\ †University of Aarhus, Faculty of Agricultural Sciences, Department of Genetics and Biotechnology, Research Centre Foulum, \\ DK-8830 Tjele, Box 50, Denmark \\ ¥Viking Genetics, Ebeltoftvej 16, DK-8900 Randers, Denmark
}

\section{ABSTRACT}

The aim of this study was to investigate whether quantitative trait loci (QTL) affecting the risk of clinical mastitis (CM) and QTL affecting somatic cell score (SCS) exhibit pathogen-specific effects on the incidence of mastitis. Bacteriological data on mastitis pathogens were used to investigate pathogen specificity of QTL affecting treatments of mastitis in first parity (CM1), second parity (CM2), and third parity (CM3), and QTL affecting SCS. The 5 most common mastitis pathogens in the Danish dairy population were analyzed: Streptococcus dysgalactiae, Escherichia coli, coagulase-negative staphylococci, Staphylococcus aureus, and Streptococcus uberis. Data were analyzed using 2 approaches: an independence test and a generalized linear mixed model. Three different data sets were used to investigate the effect of data sampling: all samples, only samples that were followed by antibiotic treatment, and samples from first-crop daughters only. The results showed with high certainty that 2 QTL affecting SCS exhibited pathogen specificity against Staph. aureus and E. coli, respectively. The latter result might be explained by a pleiotropic QTL that also affects CM2 and CM3. Less certain results were found for QTL affecting CM. A QTL affecting CM1 was found to be specific against Strep. dysgalactiae and Staph. aureus, a QTL affecting CM2 was found to be specific against $E$. coli, and finally a QTL affecting CM3 was found to be specific against Staph. aureus. None of the QTL analyzed was found to be specific against coagulase-negative staphylococci and Strep. $u b$ eris. Our results show that particular mastitis QTL are highly likely to exhibit pathogen-specificity. However, the results should be interpreted carefully because the results are sensitive to the sampling method and method of analysis. Field data were used in this study. These kind of data may be heavily biased because there is

Received August 7, 2007.

Accepted February 22, 2008

${ }^{1}$ Corresponding author: larspeter.sorensen@agrsci.dk no standard procedure for collecting milk samples for bacteriological analysis in Denmark. Furthermore, using only the mean SCS from d 10 to 180 after parturition may lead to truncated effects of SCS-QTL when samples collected after d 180 are used. Additionally, repeated samples were used, which could boost the difference in incidence of pathogens between daughters of sires inheriting the positive and negative QTL allele, respectively. However, the magnitude of these effects in this study is unclear.

Key words: quantitative trait loci, mastitis, somatic cell score, pathogen specificity

\section{INTRODUCTION}

The use of QTL in dairy cattle breeding is receiving increasing attention. In particular, QTL affecting low heritability traits are of interest because marker-assisted selection can contribute to genetic improvement of these traits. Several studies have identified QTL for SCS in dairy cattle (e.g., Ashwell et al., 1997; Zhang et al., 1998; van Tassell et al., 2000). Quantitative trait loci for clinical mastitis (CM) have been identified only in the Nordic countries because the health recording systems in these countries make this possible (e.g., Klungland et al., 2001; Holmberg and Andersson-Eklund, 2004; Schulman et al., 2004). In a recent study by Lund et al. (2008), QTL affecting CM and SCS were identified in Danish Holstein grandsire families.

Few studies have investigated pathogen-specific CM and its effects on SCC curves. However, de Haas et al. (2004) estimated associations between pathogen-specific cases of CM and SCC patterns based on deviations from a typical curve for SCC during lactation. They found that clinical Escherichia coli mastitis was associated with short peaks in SCC, whereas Staphylococcus aureus was associated with long-lasting increases in SCC. No particular SCC patterns were found for Streptococcus dysgalactiae and Streptococcus uberis. Chaffer et al. (1999) found that CNS were associated with increased SCC and caused chronic infections in heifers similar to 


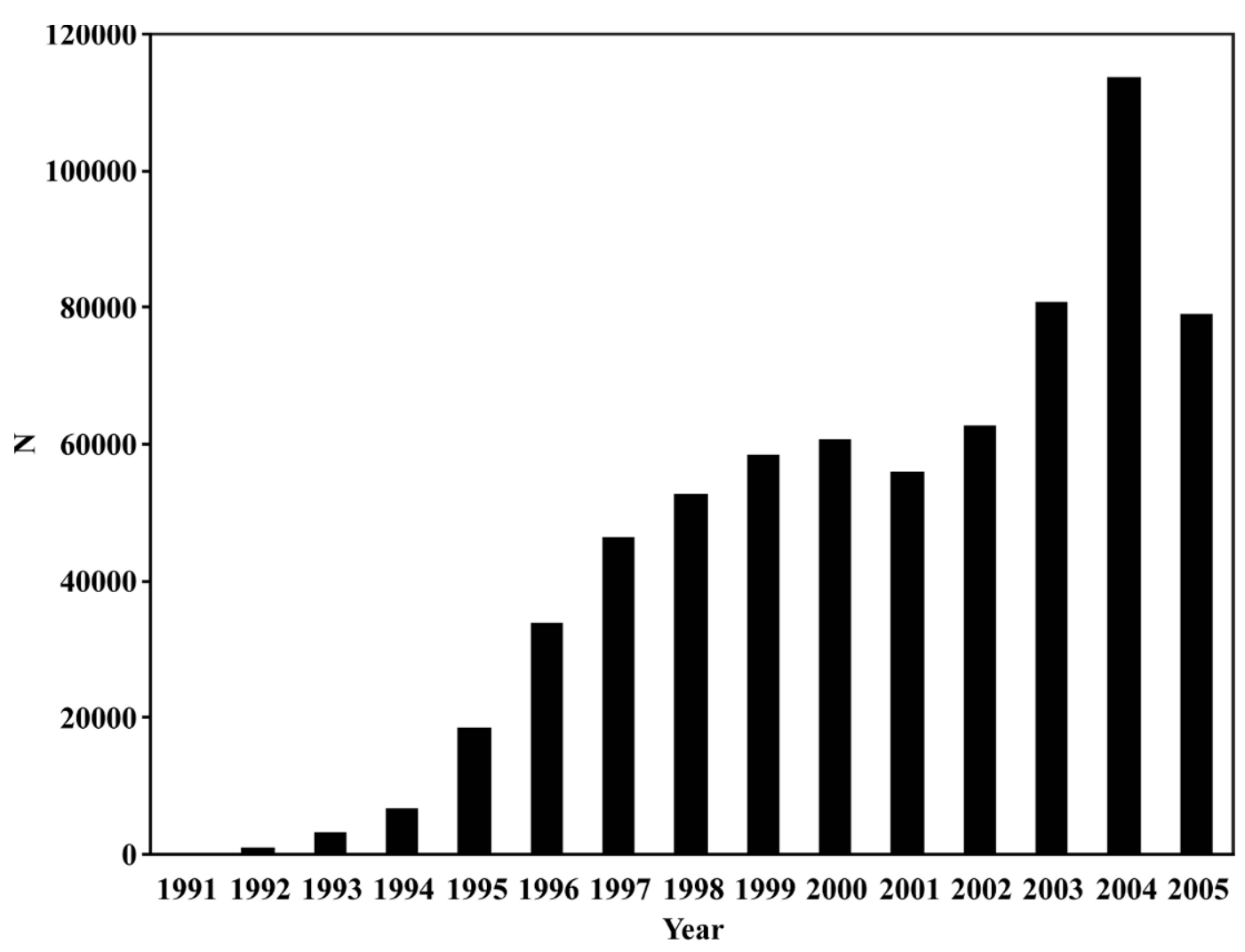

Figure 1. Total number of milk samples (N) submitted for bacteriological analysis in Denmark from 1991 to 2005 . The total number of samples in 2005 is for $260 \mathrm{~d}$ only.

those caused by Staph. aureus. These results indicate that breeding for lower SCC is more likely to reduce the number of CM due to bacteria such as Staph. aureus and CNS contrary to bacteria such as $E$. coli.

Infection patterns differ between different pathogens causing mastitis in dairy cattle, especially between gram-negative and gram-positive bacteria. For example, infections caused by $E$. coli (gram-negative) are acute and rarely become chronic (Smith and Hogan, 1993), whereas infections caused by Staph. aureus (gram-positive) are less severe but often lead to chronic infections (Sutra and Poutrel, 1994), indicated by a cyclic shedding pattern of bacteria and prolonged increased SCC. In addition, innate immune responses have been shown to differ between gram-negative and gram-positive bacteria. In a study by Bannerman et al. (2004a), innate immune responses after intramammary infections with $E$. coli and Staph. aureus were compared. This study showed that increases in cytokine IL-8 and tumor necrosis factor- $\alpha$ were observed only in quarters infected with $E$. coli. Also, the levels of complement cleavage product C5a and cytokine IL-10 were limited in quarters infected with Staph. aureus in contrast to quarters infected with $E$. coli. Innate immune response to another important gram-positive bacterium, Strep. uberis, differed greatly from that reported for Staph. aureus (Bannerman et al. 2004b). Together, these studies show that the mammary immune response in some way is pathogen-specific. It involves many molecules and pathways that can be regulated by different genes. It is therefore likely that particular QTL affecting CM or SCS provide stronger protection against particular pathogens. To our knowledge this has never been studied.

The recording system for health traits in Denmark allows for investigation of pathogen-specific effects of QTL affecting the risk of CM in the first, second, and third parities and QTL affecting SCS in first parity using results of bacteriological analyses of quarter milk samples recorded in the national database. The aim of the present study was to investigate whether QTL affecting CM and SCS found in a previous QTL study exhibited pathogen-specificity. In this context 2 hypotheses were investigated: 1) QTL affecting SCS have a specific effect on the incidence of Staph. aureus and CNS because mastitis caused by these pathogens is likely to result in increased SCC lasting for a lengthy period, and 2) QTL affecting CM have a specific effect on the incidence of $E$. coli because this pathogen often results in clinical 
Table 1. Data structure of QTL for analysis showing chromosome number (BTA), QTL positions, significance of QTL, family identification (ID), and estimated QTL effect for each trait, number of sons in data set 1 , and number of observations of pathogen data in data sets 1,2 , and 3

\begin{tabular}{|c|c|c|c|c|c|c|c|c|c|}
\hline \multirow[b]{2}{*}{ Trait $^{1}$} & \multirow[b]{2}{*}{ BTA } & \multirow{2}{*}{$\begin{array}{l}\text { QTL position, } \\
\text { cM }\end{array}$} & \multirow[b]{2}{*}{$P$-value } & \multirow{2}{*}{$\begin{array}{l}\text { Family } \\
\text { ID }\end{array}$} & \multirow{2}{*}{$\begin{array}{l}\text { QTL } \\
\text { effect }^{2}\end{array}$} & \multirow{2}{*}{$\begin{array}{l}\text { Sons, } \\
\mathrm{n}\end{array}$} & \multicolumn{3}{|c|}{ Data set, ${ }^{3} \mathrm{n}$} \\
\hline & & & & & & & 1 & 2 & 3 \\
\hline \multirow[t]{4}{*}{ SCS } & 5 & 71.9 & 0.001 & 1 & 0.044 & 100 & $21,258^{4}$ & 10,867 & 2,224 \\
\hline & & 17.4 & 0.004 & 3 & 0.042 & 74 & 9,759 & 4,688 & 1,063 \\
\hline & & 45.6 & 0.024 & 6 & 0.028 & 92 & 4,163 & 1,874 & 1,874 \\
\hline & & 59.7 & 0.051 & 13 & 0.037 & 49 & 1,651 & 871 & 1,649 \\
\hline \multirow[t]{4}{*}{ CM1 } & 15 & 13.7 & 0.001 & 1 & 1.2 & 93 & $15,657^{4}$ & 8,068 & 1,986 \\
\hline & & 103.8 & 0.004 & 2 & 1.3 & 68 & 19,564 & 10,377 & 1,440 \\
\hline & & 68.1 & 0.038 & 11 & 0.83 & 66 & 2,635 & 1,317 & 2,555 \\
\hline & & 112.0 & 0.010 & 12 & 1.5 & 43 & 1,390 & 713 & 1,382 \\
\hline \multirow[t]{3}{*}{ CM2 } & 9 & 4.4 & 0.029 & 5 & 0.73 & 102 & 5,324 & 2,880 & 2,707 \\
\hline & & 13.6 & 0.005 & 8 & 1.1 & 72 & 5,629 & 2,693 & 2,451 \\
\hline & & 15.3 & 0.045 & 9 & 0.84 & 54 & 4,881 & 2,458 & 1,889 \\
\hline \multirow[t]{2}{*}{ CM3 } & 5 & 97.5 & 0.026 & 2 & 1.0 & 68 & 19,564 & 10,377 & 1,440 \\
\hline & & 75.1 & 0.008 & 10 & 1.6 & 57 & 2,993 & 1,549 & 1,960 \\
\hline
\end{tabular}

${ }^{1} \mathrm{CM} 1, \mathrm{CM} 2$, and $\mathrm{CM} 3$ = clinical mastitis in parity 1,2 , and 3 , respectively.

${ }^{2}$ Difference in SCS units and number of cases of mastitis between daughters of sires inheriting the positive and negative QTL allele, respectively.

${ }^{3}$ The total number of observations was 189,727 in data set 1, 91,094 in data set 2, and 55,468 in data set 3

${ }^{4}$ The QTL analysis for SCS was done approximately 1 yr later than the QTL analysis for the clinical mastitis traits. In this period more sons were genotyped in this family, hence the difference in number of sons and observations.

cases. Pathogen-specific effects of QTL affecting SCS and CM against other pathogens (Strep. dysgalactiae and Strep. uberis) with less clear infection patterns were also investigated.

\section{MATERIALS AND METHODS}

\section{Collection of Data}

Bacteriological analyses of milk samples (pathogen data) collected from December 7, 1991, to September 17, 2005, were extracted from the Danish National Cattle Database. The samples were collected from mastitic cows and cows with subclinical mastitis, or as part of herd screenings in Danish Holstein herds. Collection of milk samples for bacteriological analysis is not mandatory in Denmark. Therefore, the data used in this study cannot be considered a random sample from the population. However, selection bias was assumed to be larger for samples collected before 1996 because of the relatively small number of samples (3.8\% of total number of samples) collected during this period (Figure 1); therefore, these samples were removed from the data set. The remaining samples $(n=421,714)$ from 6,220 herds had been submitted to bacteriological analysis at 196 veterinary practices. These samples were analyzed presumably according to Nylin (1996). Results of the bacteriological analyses were recorded in 20 categories with Strep. dysgalactiae, E. coli, CNS, Staph. aureus, and Strep. uberis as the most frequent with overall frequencies of
$0.112,0.118,0.104,0.156$, and 0.159 , respectively. These pathogens were selected for analysis in this study. Only the first sample taken within an 8-d period (IDF, 1987) from the same cow was included in the analyses. However, samples taken from the same cow within this 8-d period but revealing different pathogens (e.g., samples were collected from more than one quarter) were not excluded. Only daughters of genotyped sires were included in the analyses. After initial editing, the full data set (data set 1) consisted of 189,727 observations from 109,533 animals (all 20 categories included).

Treatments of mastitis recorded by veterinarians were also extracted from the Danish National Cattle Database. Treatments were recorded in 4 groups: mastitis, acute mastitis, mastitis after injury, and dry cow therapy. In the present study the 4 groups were treated as one, because an infection (clinical or subclinical) is required before antibiotic treatment is permitted to be used, and because partitioning between different recording categories was not reliable (i.e., $93.6 \%$ of treatments were in the category called mastitis). Information on mastitis treatments was merged with pathogen data if the day of treatment was $1 \mathrm{~d}$ before to $5 \mathrm{~d}$ after the recorded date of a pathogen.

Two additional data sets were extracted from data set 1 to investigate the effect of data sampling. Data set 2 contained observations only from cows treated for mastitis at the time of sampling $(n=91,094)$. With this approach we know that cows were tested for pathogens 
because of clinical signs for mastitis, and can make analyses conditional on this fact. Data may be heavily unbalanced because of older sires with more than first-crop daughters. Therefore, in data set 3 , only recordings from first-crop daughters, defined as cows born no later than $5 \mathrm{yr}$ after the birth of the sire were included in this data set $(\mathrm{n}=55,468)$.

\section{Selection of Families and QTL Positions}

The QTL for analysis in this study (Table 1) were chosen from a previous QTL study that is presented in part in Lund et al. (2008). Among the significant QTL in across-family analyses, chromosomes were selected in which at least 2 grandsire families were segregating. The chosen QTL were associated with treatments of mastitis from -10 to $305 \mathrm{~d}$ after parturition in first parity (CM1), second parity (CM2), third parity (CM3), and SCS, which was calculated as the mean SCS 10 to 180 $\mathrm{d}$ after first calving. Each grandsire family was required to have at least 1,000 observations in data set 2 . This could not be achieved in families 12 and 13, in which the number of observations was 713 and 871, respectively. Thus, these families were not analyzed in data set 2 but were included in the analyses of data sets 1 and 3 , as they have more daughters. For the selected QTL, positions were estimated for each grandsire family separately.

\section{Statistical Analyses}

Data were analyzed using 2 approaches: an independence test ( $\chi^{2}$ test) for analysis of all 3 data sets and a generalized linear mixed model (GLMM) for analysis of the full data set. The present study was designed only to detect positive pathogen-specific effects of the positive allele $(\mathbf{Q})$, which is equivalent to a significant lower pathogen frequency in the $\mathrm{Q}$ group. The true frequency of positive bacteriological samples is expected to be lower in daughters of sires inheriting the $\mathrm{Q}$ allele than in daughters of sires inheriting the negative allele (q), because there is an effect of the QTL on mastitis incidence in general. Consequently, the relative incidence of a given pathogen can actually be lowest in the $q$ group indicated by a negative or neutral pathogen-specific effect (Figure 2).

Independence Test. Within each grandsire family, observations (daughters) were grouped by sires that inherited Q and sires that inherited q from the heterozygous grandsire. Here, Q resulted in fewer cases of mastitis or lower SCS. The sires were assumed to have inherited a specific allele when the probability of inheritance was more than $90 \%$. An independence test was used to investigate whether the number of samples for a specific pathogen per total number of samples (frequency) differed between the $\mathrm{Q}$ and $\mathrm{q}$ groups, $\mathrm{H}_{0}: P_{\mathrm{q}}=P_{\mathrm{Q}}$, where $P_{\mathrm{q}}$ and $P_{\mathrm{Q}}$ are the frequency of a specific pathogen in the 2 groups, $\mathrm{q}$ and $\mathrm{Q}$. Extreme test values $(P<0.05)$ indicated a pathogen-specific QTL effect. Using the independence test, a total of 65,55 , and 65 tests were carried out for data sets 1,2 , and 3, respectively. A total of 65 tests were carried out using the GLMM.

GLMM Analysis. Changes in sampling strategies, common environmental effects, and other polygenetic effects might distort the pathogen-specific effect of the QTL when an independence test is used. To account for this, a GLMM was fitted on data from data set 1:

$$
\begin{gathered}
\log \frac{\pi_{i j}}{1-\pi_{i j}}=\beta P_{i}+\beta_{L j} P_{i}+L_{j}+Y_{i}+(L \\
\times Y)_{i j}+h_{i}+s_{i}+e_{i j}
\end{gathered}
$$

where $\pi_{i j}=$ probability to get a specific pathogen for observation $i$ in parity $j ; i=(1, \ldots, \mathrm{n}) ; j=(1,>1) ; P_{i}=$ probability to inherit $\mathrm{Q}$ from the grandsire; $L_{j}=$ fixed effect of parity; $Y_{i}=$ fixed effect of year; $(L \times Y)_{i j}=$ fixed effect of interaction between parity and year; $\beta=$ regression coefficient of $P_{i} ; \beta_{L j} P_{i}=$ nested effect of segregation probability within parity (as different QTL effects may be seen in different parities due to the high genetic correlation between the incidence of mastitis in successive parities; Danish Cattle Federation, 2006); $h_{i}=$ random effect of herd; and $s_{i}=$ random effect of sire.

The model assumes that $D_{i} \mid\left(h_{i}, s_{i}\right) \sim \operatorname{Bernoulli}\left(\pi_{i j}\right)$, where $D_{i}$ is an indicator for the detection of a specific pathogen (i.e., $D_{i}=1$ if pathogen is detected and 0 otherwise). Moreover, it is assumed that herd and sire effects were normally distributed and independent:

$$
h_{i} \sim N\left(0, \gamma^{2}\right) \text { and } s_{i} \sim N\left(0, \phi^{2}\right) \text { for all } i
$$

and the residual was fixed at $e_{i j} \sim N(0,1)$.

The GLMM analyses were run using the GLIMMIX macro for SAS (version 8, SAS Institute Inc., 1999). Marginal quasi-likelihood was used to estimate parameters and a convergence criterion of $10^{-8}$ was used. Pathogenspecific effects of the QTL were assumed when significant effects of $\beta_{i}$ or $\beta_{L j}$ were detected $(P<0.05)$.

Multiple Testing. The risk for making wrong inferences increases with the number of statistical tests performed. To take the increased false-positive rate into account we applied the method of Benjamini and Hochberg (1995) for controlling the false discovery rate (FDR). Let $P_{(1)} \leq P_{(2)} \leq \ldots \leq P_{(m)}$ be the ordered $p$-values for each combination of data set and method of analysis, and denote by $H_{(\mathrm{i})}$ the null hypothesis corresponding to $P_{(\mathrm{i})}$. Then, let $k$ be the largest $i$ for which $P_{(i)} \leq \frac{i}{m} q^{*}$, and 

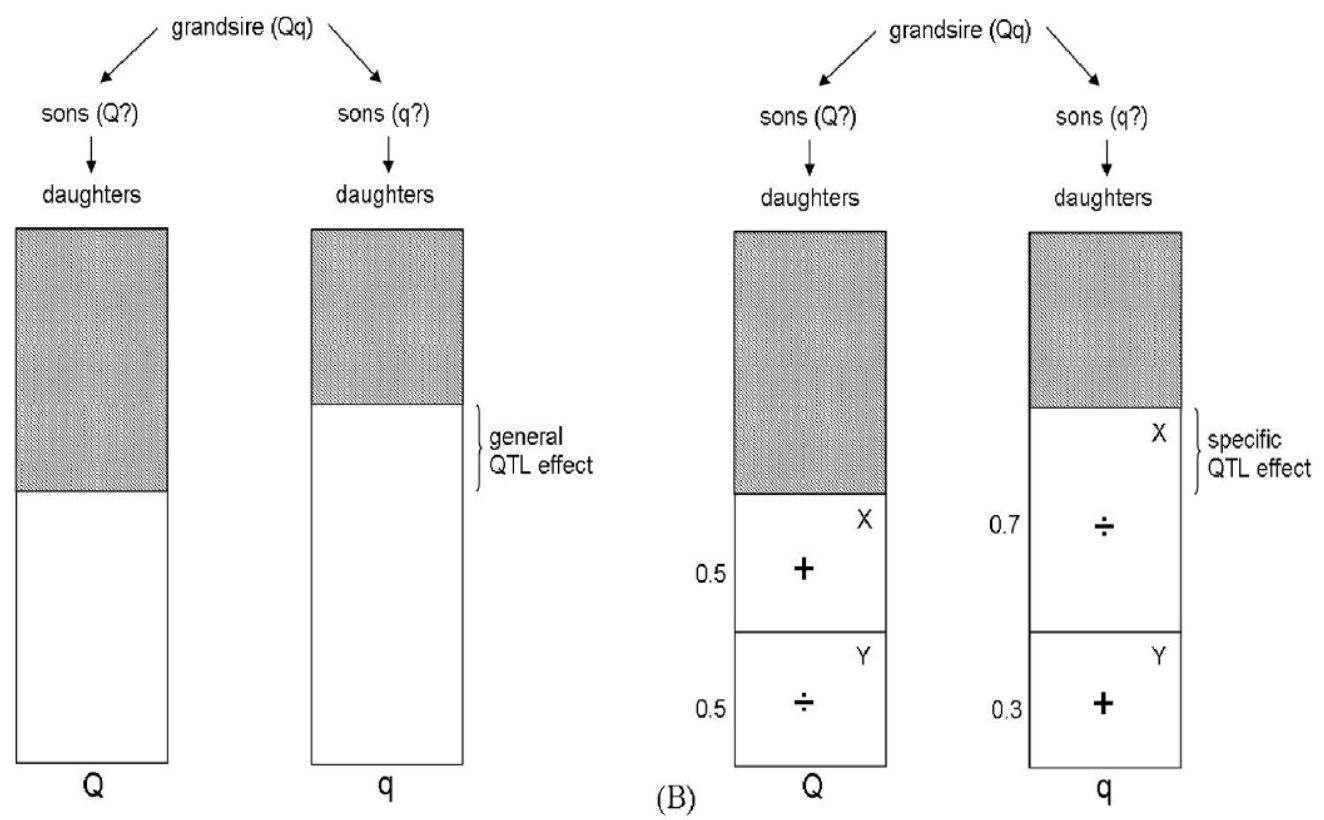

Figure 2. The traditional grandsire design for detecting QTL effects in dairy cattle. Each column represents the total number of daughters of sons inheriting the $\mathrm{Q}$ and q allele, respectively, from a common grandsire. In (A) the general QTL effect is the difference of, for example, the number of cases of mastitis between the $\mathrm{Q}$ and q groups. The shaded areas represent an unknown number of daughters not included in the present design. In (B) we are looking at pathogen-specific effects. For simplicity, only 2 pathogens are shown here, X and Y. Each has a frequency of 0.5 in the $\mathrm{Q}$ group, whereas $\mathrm{X}$ and $\mathrm{Y}$ have frequencies of 0.7 and 0.3 , respectively, in the q group. These frequencies are not equal to the relative frequencies, which are unknown. In this setup there is a positive pathogen-specific effect of $Q$ on pathogen $X$. However, we fail to detect that the effect on pathogen $\mathrm{Y}$ is, in fact, a neutral effect. Instead, we get a negative pathogen-specific effect of the $\mathrm{Q}$ allele on pathogen Y.

reject all $H_{(\mathrm{i})}, i=1,2, \ldots, k$. The FDR was controlled at $q^{*}=$ 0.05 , and $m$ is the number of tests for each combination of method of analysis and data set.

Odds Ratio. Odds ratios (OR) were calculated in cases where significant pathogen-specific effects were found. The OR are defined as the odds to get a specific pathogen given $\mathrm{Q}$, relative to the odds to get the same pathogen given $\mathrm{q}$, given that a cow was sampled for pathogen assessment $\left(\mathbf{O R}_{\mathbf{Q q}}\right)$. An $\mathrm{OR}_{\mathrm{Qq}}<1$ indicates a lower risk of getting a specific pathogen if $Q$ was inherited. It is not possible to determine whether the effect of the $\mathrm{Q}$ allele is neutral or negative when $\mathrm{OR}_{\mathrm{Qq}}>1$ following the experimental design of this study. Odds ratios and confidence intervals were calculated for independence tests and GLMM analyses.

\section{RESULTS}

\section{Analysis of Pathogen Specificity}

Results of the analysis of pathogen-specific effects are given in Table 2. Using the independence test on data sets 1,2 , and 3 , the number of significant pathogenspecific effects was 9,4 , and 2, respectively. For analysis of data set 1 with the GLMM, 6 significant results were found. However, controlling FDR clearly reduced the number of pathogen-specific effects. Results satisfying $P_{(i)} \leq \frac{i}{m} q^{*}$ are marked with an asterisk in Table 2 and were 5,4 , and 1 for data sets 1,2 , and 3 , respectively, using the independence test, and 3 using the GLMM on data set 1. Following this, pathogen-specific effects of QTL affecting SCS were found on Bos taurus autosome (BTA) 5 at $71.9 \mathrm{cM}$ (E. coli) and BTA5 at $45.6 \mathrm{cM}$ (Staph. aureus). Highly significant test results were found in analysis of all combinations of method of analysis and data set for the QTL affecting Staph. aureus. This was also the case for the QTL affecting $E$. coli except for analysis of data set 2 using the independence test.

A pathogen-specific effect against Strep. dysgalactiae was found for the QTL on BTA5 at $103.8 \mathrm{cM}$ affecting CM1 in analysis of data sets 1 and 2 using the independence test. The same QTL was also found to be specific against Staph. aureus in analysis of data set 1 using the independence test. The QTL affecting CM2 on BTA9 at $13.6 \mathrm{cM}$ was found to be specific against $E$. coli in analysis of data sets 1 and 2 using the independence test. Finally, using the GLMM, the QTL on BTA5 at $97.5 \mathrm{cM}$ affecting CM3 was found to be specific against Staph. aureus. No significant test results were found for CNS and Strep. uberis. 
Table 2. Results from analyses (independence test and generalized linear mixed model, GLMM) of pathogenspecific effects of QTL against specific pathogens ${ }^{1}$

\begin{tabular}{|c|c|c|c|c|c|c|}
\hline \multirow[b]{2}{*}{ Trait $^{2}$} & \multirow[b]{2}{*}{$\begin{array}{c}\text { QTL } \\
\text { position }\end{array}$} & \multirow[b]{2}{*}{ Pathogen $^{3}$} & \multicolumn{3}{|c|}{ Independence test } & \multirow{2}{*}{$\frac{\text { GLMM }}{\begin{array}{c}\text { Data set } 1 \\
P \text {-value }\end{array}}$} \\
\hline & & & $\begin{array}{c}\text { Data set } 1 \\
P \text {-value }\end{array}$ & $\begin{array}{l}\text { Data set } 2 \\
P \text {-value }\end{array}$ & $\begin{array}{c}\text { Data set } 3 \\
P \text {-value }\end{array}$ & \\
\hline \multirow[t]{2}{*}{ SCS } & $\begin{array}{l}\text { Bos taurus autosome } \\
\text { (BTA) } 5,71.9 \mathrm{cM}\end{array}$ & COLI & $<0.001^{*}$ & $<0.001^{*}$ & 0.144 & $<0.001^{* 4}$ \\
\hline & BTA5, $45.6 \mathrm{cM}$ & AUREUS & $<0.001^{*}$ & $<0.001^{*}$ & $<0.001^{*}$ & $<0.001^{* 4}$ \\
\hline \multirow[t]{4}{*}{ CM1 } & BTA15, $103.8 \mathrm{cM}$ & DYSGAL & $<0.001^{*}$ & $0.002 *$ & 0.405 & $0.266^{4}$ \\
\hline & & CNS & 0.021 & 0.261 & 0.315 & $0.091^{4}$ \\
\hline & & AUREUS & $<0.001^{*}$ & 0.749 & 0.635 & 0.005 \\
\hline & BTA15, $112.0 \mathrm{cM}$ & CNS & 0.669 & - & 0.624 & $0.029^{5}$ \\
\hline \multirow[t]{4}{*}{ CM2 } & BTA9, $4.4 \mathrm{cM}$ & AUREUS & 0.045 & 0.332 & 0.007 & 0.915 \\
\hline & BTA9, $13.6 \mathrm{cM}$ & COLI & $0.004 *$ & $0.002^{*}$ & 0.634 & 0.693 \\
\hline & & CNS & 0.006 & 0.097 & 0.817 & 0.914 \\
\hline & BTA9, $15.3 \mathrm{cM}$ & AUREUS & 0.101 & 0.645 & 0.012 & 0.127 \\
\hline \multirow[t]{2}{*}{ CM3 } & BTA5, $97.5 \mathrm{cM}$ & COLI & 0.041 & 0.825 & 0.815 & $0.041^{4}$ \\
\hline & & AUREUS & 0.260 & 0.459 & 0.703 & $<0.001^{* 4}$ \\
\hline
\end{tabular}

${ }^{1} P$-values marked with $*$ satisfy $P_{(i)} \leq \frac{i}{m} q^{*}$ at $q^{*}=0.05$.

${ }^{2} \mathrm{CM} 1, \mathrm{CM} 2$, and CM3 = clinical mastitis in parity 1,2 , and 3 , respectively.

${ }^{3}$ DYSGAL $=$ Strep. dysgalactiae $;$ COLI $=E$. coli; AUREUS $=$ Staph. aureus.

${ }^{4}$ Reduced model.

${ }^{5}$ Only positive effect of this QTL in parity $>1$.

\section{QTL Effects}

The $\mathrm{OR}_{\mathrm{Qq}}$ values (Table 3) were calculated for all significant positive QTL effects. In general, the difference in risks of getting a specific pathogen between the $q$ and $\mathrm{Q}$ groups was small. Based on our results, the risk for getting a specific pathogen for a daughter of a sire of the q group was 1.3 to 1.6 greater than for a daughter of a sire in the Q group, depending on pathogen, QTL, and method of analysis. For example, the relative difference in frequency of Staph. aureus between the Q and $q$ groups was 0.05 . No differences were found for $\mathrm{OR}_{\mathrm{Qq}}$ where significant test results were found using both methods. However, the confidence intervals were larger for $\mathrm{OR}_{\mathrm{Qq}}$ calculated from the GLMM.

\section{Fixed Effects}

In several cases, it was not possible to fit the full GLMM due to lack of convergence. In these cases (Table 2 ), the model was reduced by removing effect of parity from the model. Thus, it was not possible to detect any effect of parity on incidence of pathogens. Significant effects of year were found for almost all the analyzed QTL (results are not shown as years and number of years varied between grandsire families).

\section{DISCUSSION}

In this study, we investigated whether QTL that previously had been shown to affect SCS and the risk of

Table 3. Odds ratios $\left(\mathrm{OR}_{\mathrm{Qq}}\right)$ and $95 \%$ confidence intervals (in brackets) for the odds of getting a specific pathogen given $\mathrm{Q}$ relative to getting the same pathogen given $\mathrm{q}^{1}$

\begin{tabular}{|c|c|c|c|c|}
\hline Trait $^{2}$ & QTL position & Pathogen $^{3}$ & $\begin{array}{l}\text { Independence } \\
\text { test }\end{array}$ & GLMM $^{4}$ \\
\hline \multirow[t]{2}{*}{ SCS } & $\begin{array}{l}\text { Bos taurus autosome } \\
\text { (BTA) } 5,71.9 \mathrm{cM}\end{array}$ & COLI & $0.73[0.72 ; 0.74]$ & $0.73[0.67 ; 0.79]$ \\
\hline & BTA5, $45.6 \mathrm{cM}$ & AUREUS & $0.73[0.72 ; 0.74]$ & $0.63[0.55 ; 0.72]$ \\
\hline \multirow[t]{2}{*}{ CM1 } & BTA15, $103.8 \mathrm{cM}$ & DYSGAL & $0.69[0.67 ; 0.70]$ & \\
\hline & & AUREUS & $0.74[0.73 ; 0.75]$ & \\
\hline CM2 & BTA9, $13.6 \mathrm{cM}$ & COLI & $0.75[0.73 ; 0.76]$ & \\
\hline CM3 & BTA5, $97.5 \mathrm{cM}$ & AUREUS & & $0.66[0.58 ; 0.75]$ \\
\hline
\end{tabular}

${ }^{1} \mathrm{OR}_{\mathrm{Qq}}$ for the independence tests are based on analyses of the full data set.

${ }^{2} \mathrm{CM} 1, \mathrm{CM} 2$, and $\mathrm{CM} 3$ = clinical mastitis in parity 1,2 , and 3 , respectively.

${ }^{3}$ DYSGAL $=$ Strep. dysgalactiae COLI $=E$. coli , AUREUS $=$ Staph. aureus.

${ }^{4} \mathrm{GLMM}=$ generalized linear mixed model. 
being treated for mastitis exhibited a specific effect on the incidence of the 5 most common pathogens in the Danish Holstein population. Results, although not highly convincing, showed that QTL are, in part, pathogen-specific and that QTL affecting CM are likely to affect $E$. coli but also Staph. aureus and Strep. dysgalactiae, whereas QTL affecting SCS are likely to affect Staph. aureus but also $E$. coli. Highly significant test results were found for a QTL on BTA5 at $45.6 \mathrm{cM}$ affecting SCS in analyses of all data sets using both methods of analysis. This gives a high degree of certainty that this QTL exhibits a pathogen-specific effect on the incidence of Staph. aureus mastitis. This was expected, because Staph. aureus predominantly leads to long-term subclinical infections, indicated by persistently elevated SCC (de Haas et al., 2004) and thereby affects lactation SCS. For another SCS-QTL, BTA5 at $71.9 \mathrm{cM}$, highly significant test results were found using both methods of analysis except in analysis of data set 3, probably because of the substantially smaller number of observations in this data set, which decreases the power of detecting significant effects. This QTL was found to be specific against $E$. coli. From a biological viewpoint, this result was not expected, because it is less likely that cases of mastitis caused by $E$. coli will affect lactation SCC. According to Shook and Schutz (1994), a monthly sampling scheme for SCC will capture only 10 to $20 \%$ of infections caused by $E$. coli. However, Lund et al. (2008) found that this particular QTL was pleiotropic affecting SCS, CM2, and CM3. Genetic map distances between peaks in a 2-QTL linkage model were found to be $6 \mathrm{cM}$ for SCS and CM2 and $16 \mathrm{cM}$ for SCS and CM3, and a pleiotropic model was favored over a linkage model. According to this information, our result for $E$. coli seems reasonable, because this QTL affects CM. Pathogen-specific effects of a QTL affecting CM1 were found against Strep. dysgalactiae and Staph. aureus (BTA15 at $103.8 \mathrm{cM}$ ). A pathogen-specific effect of a QTL affecting CM2 was found against $E$. coli (BTA9 at 13.6 $\mathrm{cM}$ ), and a pathogen-specific effect of a QTL affecting CM3 was found against Staph. aureus (BTA5 at 97.5 $\mathrm{cM})$. However, these results were not supported using both methods of analysis and are, therefore, less certain.

The question remains whether the results found in this study are real or a result of data sampling. Bacteriological analysis of milk samples drawn from cows suspected to have clinical or subclinical mastitis is not mandatory in Denmark. Thus, selection bias can be expected and results should be interpreted with care. However, looking at the number of milk samples submitted for bacteriological analysis each year (Figure 1), it could be argued that selection bias decreases as the number of samples increases. Additional information on each bacteriological sample would be valuable for future studies (e.g., registrations on which quarter the sample was taken from, the reason for taking the sample, if the sample was followed by antibiotic treatment, and so on). For mastitis treatments, it would also be useful to have more information such as which quarter was treated and the degree of acuteness (e.g., acute, mild clinical, subclinical). This information would make it clearer which samples to use when investigating pathogen-specific effects. In the present study, we used repeated samples from each animal. This could boost the difference in incidence of pathogens between the $\mathrm{Q}$ and $\mathrm{q}$ groups because of more information from sick animals and subsequent larger difference in incidence between real QTL groups. However, the variance is also larger. Hence, for small effects, the power of detection is reduced and for larger QTL effects the power may be increased. However, in this study the size of bias in data remains unknown and this should be taken into account when interpreting the results.

In the study by Lund et al. (2008), SCS was defined as the mean SCS from 10 to $180 \mathrm{~d}$ after parturition. This model is ineffective to capture short-term variation in SCC as seen in the case of $E$. coli, but may still capture variation due to pathogens associated with prolonged elevated SCC (e.g., Staph. aureus and CNS). However, using SCS from 10 to $180 \mathrm{~d}$ after parturition only may lead to truncation of effects because of pathogens such as Staph. aureus, especially if mastitis due to these pathogens is recorded after $d 180$. In this study, approximately $50 \%$ of recorded Staph. aureus cases were seen from 10 to $180 \mathrm{~d}$ after parturition. The effect of truncation is unclear, but the possibility exists that the effects found for the SCS QTL in this study are overestimated.

Data editing might change the relative pathogen frequencies, which could explain the differences in detected pathogen-specific QTL. Only one QTL result on BTA9 at $15.3 \mathrm{cM}$ showed significant specificity when data set 3 was used. No significance was found when data sets 1 and 2 were used (although this result was not taken into account when control of FDR was applied). There are 2 possible explanations for this. First, the number of observations was considerably less in data set 3 , excluding valuable information and thereby decreasing the power to detect differences in pathogen frequencies between the $\mathrm{Q}$ and q groups. Second, in data sets 1 and 2 , a large proportion of the data were from daughters of proven bulls. Differences between these bulls from factors other than the QTL may have led to spurious results. Data set 3 included observations from first-crop daughters only, which reduced the variation in number of observations per bull. Data set 2 included observations only where the cow had been treated for mastitis at the time of sampling. In this case, sterile samples and samples from mild cases of mastitis not receiving treat- 
ment were removed from the data set. As a result, the number of repeated samples per cow was less in data set 2 . This might have changed the relative frequency of the investigated pathogens, thereby leaving some pathogen-specific effects undetected. However, results from using this data set were in agreement with the results obtained from analysis of data set 1 , except in one case (BTA15 at $103.8 \mathrm{cM}$ ).

Two methods of analysis were used in this study: an independence test and a GLMM. The independence test is advantageous in some cases because it is robust and easy to apply, and the results are easy interpretable. However, different results were found using this method on different editing procedures, indicating sensibility to data structure, and in our case the assumption of independence is unlikely to be met, because, on average, 1.73 observations were available for each animal (data set 1), either from the same parity or from different parities. The GLMM takes data distribution into account, but in our case the model was often difficult to fit, probably due to extreme category problems (Misztal et al., 1989). The significant results using this method were all found using a reduced model, which makes the interpretation of the results less reliable compared with running the full model. Additionally, in several cases, random effects were found to be zero, indicating an infinite likelihood. For these reasons, it was important to use different sampling and analysis methods, and confidence in the results is greatly increased when results were consistent across analyses.

\section{ACKNOWLEDGMENTS}

Recordings of bacteriological analyses of milk samples and information on mastitis treatments were kindly provided by the Danish Cattle Federation (Aarhus, Denmark).

\section{REFERENCES}

Ashwell, M. S., C. E. Rexroad, R. H. Miller, P. M. VanRaden, and Y. Da. 1997. Detection of loci affecting milk production and health traits in an elite US Holstein population using microsatellite markers. Anim. Genet. 28:216-222.

Bannerman, D. D., M. J. Paape, J. P. Goff, K. Kimura, J. D. Lippolis, and J. C. Hope. 2004b. Innate immune response to intramammary infection with Serratia marcescens and Streptococcus uberis. Vet. Res. 35:681-700.
Bannerman, D. D., M. J. Paape, J.-W. Lee, X. Zhao, J. C. Hope, and P. Rainard. 2004a. Escherichia coli and Staphylococcus aureus elicit differential innate immune response following intramammary infection. Clin. Diagn. Lab. Immunol. 11:463-472.

Benjamini, Y., and Y. Hochberg. 1995. Controlling the false discovery rate: A practical and powerful approach to multiple testing. J. R. Stat. Soc. Ser. B Stat. Methodol. 57:289-300.

Chaffer, M., G. Leitner, M. Winkler, A. Glickman, O. Krifucks, E. Ezra, and A. Saran. 1999. Coagulase-negative staphylococci and mammary gland infections in cows. J. Vet. Med. B Infect. Dis. Vet. Public Health 46:707-712.

Danish Cattle Federation. 2006. Principles of Danish cattle breeding. http://r.dk/kvaeg/diverse/principles.pdf. Accessed Oct. 18, 2007.

de Haas, Y., R. F. Veerkamp, H. W. Barkema, Y. T. Gröhn, and Y. H. Schukken. 2004. Associations between pathogen-specific cases of clinical mastitis and somatic cell count patterns. J. Dairy Sci. $87: 95-105$.

Holmberg, M., and L. Andersson-Eklund. 2004. Quantitative trait loci affecting health traits in Swedish dairy cattle. J. Dairy Sci. 87:2653-2659.

IDF. 1987. Bovine mastitis. Definition and guidelines for diagnosis. Bull. Int. Dairy Fed. 211. IDF, Brussels, Belgium.

Klungland, H., A. Sabry, B. Heringstad, H. G. Olsen, L. Gomez-Raya, D. I. Våge, I. Olsaker, J. Ødegård, G. Klemetsdal, N. Sculman, J. Vilkki, J. Ruane, M. Aasland, K. Rønningen, and S. Lien. 2001. Quantitative trait loci affecting clinical mastitis and somatic cell count in dairy cattle. Mamm. Genome 12:837-842.

Lund, M. S., B. Guldbrandtsen, A. J. Buitenhuis, B. Thomsen, and C. Bendixen. 2008. Detection of quantitative trait loci in Danish Holstein cattle affecting clinical mastitis, somatic cell score, udder conformation traits, and assessment of associated effects on milk yield. J. Dairy Sci. 91:In press..

Misztal, I., D. Gianola, and J. L. Foulley. 1989. Computing aspects of a nonlinear method of sire evaluation for categorical data. J. Dairy Sci. 72:1557-1568.

Nylin, B. 1996. Use of esculin-blood agar as a diagnostic tool in acute bovine mastitis. Pages 270-273 in Proc. XIX World Buiatrics Congr., Edinburgh, UK. Br. Cattle Vet. Assoc., Frampton-on-Severn, UK.

SAS Institute. 1999. SAS User's Guide: Statistics. Version 8. SAS Institute Inc., Cary, NC.

Schulman, N. F., S. M. Viitala, D. J. de Koning, J. Virta, A. MäkiTanila, and J. H. Vilkki. 2004. Quantitative trait loci for health traits in Finnish Ayrshire cattle. J. Dairy Sci. 87:443-449.

Shook, G. E., and M. M. Schutz. 1994. Selection on somatic cell score to improve resistance to mastitis in the United States. J. Dairy Sci. 77:648-658.

Smith, K. L., and J. S. Hogan. 1993. Environmental mastitis. Vet. Clin. North Am. Food Anim. Pract. 9:489-498.

Sutra, L., and B. Poutrel. 1994. Virulence factors involved in the pathogenesis of bovine intramammary infections due to Staphylococcus aureus. J. Med. Microbiol. 40:79-89.

van Tassell, C. P., M. S. Ashwell, and T. S. Sonstegard. 2000. Detection of putative loci affecting milk, health, and conformation traits in a US Holstein population using 105 microsatellite markers. J. Dairy Sci. 83:1865-1872.

Zhang, Q., D. Boichard, I. Hoeschele, C. Ernst, A. Eggen, B. Murkve, M. Pfister-Genskow, L. A. Witte, F. E. Grignola, P. Uimari, G. Thaller, and M. D. Bishop. 1998. Mapping quantitative loci for milk production and health of dairy cattle in a large outbred population. Genetics 149:1959-1973. 